\title{
ANALISA PENGARUH SELF IMAGE CONGRUITY, RETAIL SERVICE QUALITY, DAN CUSTOMER PERCEIVED SERVICE QUALITY TERHADAP CUSTOMER LOYALTY YANG DIMEDIASI CUSTOMER SATISFACTION URBAN SURF DI JAYAPURA
}

\author{
Milcha Handayani Tammubua \\ Manajemen FEB UPBJJ-UT Jayapura \\ email: milcha@ecampus.ut.ac.id
}

\begin{abstract}
This study aims to examine whether self image congruity, retail service quality, perceived service quality influence customer satisfaction and test the role of customer satisfaction mediation variable at customer loyalty distro Urban Surf and Planet Surf in Jayapura. data analysis in this research used multiple regression analysis and hierarical regression to measure independent variable in dependent variable with mediation variable. The results show that customer satisfaction fully mediates the relationship of self image congruity and retail service quality to customer loyalty. Meanwhile customer satisfaction also mediates partially customer relationship perceived service quality to customer loyalty.
\end{abstract}

Keywords: customer loyalty, customer perceived service quality, customer satisfaction, retail service quality, self image congruity

\begin{abstract}
ABSTRAK
Penelitian ini bertujuan untuk mengkaji apakah self image congruity, retail service quality, perceived service quality berpengaruh pada customer satisfaction dan menguji peran mediasi variable customer satisfaction pada customer loyalty distro Urban Surf dan Planet Surf di Jayapura. Analisis data dalam penelitian ini digunakan analisis multiple regression dan hierarical regression untuk mengukur variable independen pada variable dependen dengan variable mediasi. Hasil penelitian menunjukkan bahwa customer satisfaction memediasi secara penuh hubungan self image congruity dan retail service quality terhadap customer loyalty. Sementara itu customer satisfaction juga memediasi secara parsial hubungan customer perceived service quality terhadap customer loyalty.
\end{abstract}

Kata kunci: customer loyalty, customer perceived service quality, customer satisfaction, retail service quality, self image congruity

Segmen dan target pasar dari Distro adalah usia remaja hingga pemuda. Oleh sebab itu Distro berkembang dengan sangat cepat di berbagai kota besar yang memiliki jumlah penduduk cukup besar dengan kategori usia remaja hingga pemuda. Perkembangan Distro (Distribution Store/Outlet) di kota Jayapura masih sangat sedikit, tidak seperti kota-kota besar di pulau Jawa, Sumatera, Sulawesi, meskipun telah terjadi peningkatan jumlah penduduk di kota Jayapura dengan kategori usia 15-24 selama 5 tahun terakhir, yaitu sebesar 34\%, yang berasal dari luar Papua yang 
datang dan menetap di Jayapura. Hasil wawancara singkat dengan responden sampel penelitian di kota Jayapura, responden merasakan menjadi pribadi yang unik, bebas, dan merasa 'keren' ketika melakukan pembelian produk fashion baik itu pakaian maupun aksesoris di Urban Surf/Planet Surf. Ini merupakan peluang pasar yang harus dimanfaatkan dengan baik oleh para pelaku bisnis yang bergerak di usaha distro. Oleh sebab itu pelaku bisnis yang bergerak di bidang distro perlu mengetahui variable-variabel yang diduga berpengaruh signifikan pada kepuasan pelanggan dan dari kepuasan pelanggan yang tercipta diharapkan terjadi loyalitas pelanggan.

Sementara itu aktivitas pembelian produk kategori 'fashion' telah menjadi bagian dari lifestyle. Hal ini menciptakan sebuah perspektif di dalam diri konsumen, yaitu merasa telah meningkatkan citra dirinya ketika telah melakukan pembelian produk kategori 'fashion' (Schifman dan Kanuk, 2007). Oleh sebab itu pemasar akan berusaha untuk menciptakan berbagai rangsangan yang dapat membuat konsumen betah/nyaman selama melakukan kegiatan pembelian, dan diharapkan konsumen dapat menjadi pelanggan yang loyal. Schifman dan Kanuk (2007) menyatakan bahwa sebuah toko (dalam hal ini distro) harus mampu memenuhi kebutuhan sosial konsumen dan juga harus mampu mencerminkan karakter maupun status sosial konsumen. Konsumen akan memilih barang dan jasa yang memiliki "kecocokan" dengan citra dirinya.

Definisi atau pengertian dari distro adalah jenis toko di Indonesia yang menjual pakaian dan aksesori yang dititipkan oleh pembuat pakaian, atau diproduksi sendiri. Distro umumnya merupakan Industri Kecil dan Menengah (IKM) yang sandang dengan merek independen yang dikembangkan kalangan anak muda. Produk yang dihasilkan oleh distro diusahakan untuk tidak diproduksi secara massal, agar mempertahankan sifat ekslusif suatu produk dan hasil kerajinan. Untuk daerah Jayapura beberapa toko yang masuk kategori distro adalah Urban Surf, Planet Surf. Adapun desain dan interior Urban Surf maupun Planet Surf mengusung nuansa yang kental dengan selera kalangan anak muda seperti dinding ruangan toko yang bermotif mozaik dan sebagian area berwarna putih maupun hitam dilengkapi dengan alat multimedia audio-visual seperti televisi yang menampilkan cuplikan video sport yang digemari oleh anak muda seperti skateboarding, surfing, bike, motorcross. Adapun lantai ruangan dilapisi oleh papan kayu berwarna coklat, dan diiringi dengan music bernuansa rock dan metal. Pramuniaga Urban Surf juga menggunakan seragam yang casual dan santai sehingga menciptakan suasana santai bagi para pengunjung. Konsep seperti ini akan menciptakan persepsi konsumen akan penilaian kualitas pelayanan distro. Menurut Durianto, dkk dalam Livia dan Edwin (2015) Persepsi konsumen akan keseluruhan kualitas atau keunikan suatu layanan/produk berkaitan dengan harapan konsumen. Persepsi yang timbul akan kualitas Urban Surf maupun Planet Surf adalah Sporty, Ekslusif dan "Gaul”, bahwa konsumen khususnya anak muda merasa lebih percaya diri dan merasa dapat meningkatkan status sosialnya ketika menggunakan pakaian maupun aksesoris yang ditawarkan oleh distro tersebut. Hal ini disebabkan mulai dari suasana hingga pramuniaga yang mengenakan pakaian casual. Model pakaian maupun aksesoris yang ditawarkan juga mengikuti tren yang berkembang saat ini.

Menurut Schiffman dan Kanuk (2007), tiap-tiap konsumen memiliki cerminan tentang dirinya. Tindakan yang dilakukan oleh konsumen seperti keputusan pembelian, bergantung pada self concept konsumen tersebut. Persepsi mengenai diri erat kaitannya dengan kepribadian, bahwa konsumen cenderung membeli dan menggunakan produk berupa barang maupun jasa serta menjadi pelanggan perusahaan yang mempunyai citra atau "kepribadian" yang sesuai dengan citra diri mereka. Pada dasarnya tiap konsumen berusaha menggambarkan diri mereka pada pelbagai pilihan merek. Secara teoritis, beberapa penelitian terdahulu yang dilakukan oleh Jamal dan Goode (2001); Wilkins, et al. (2006), Park dan Lee, (2005) memaparkan bahwa self image congruity berpengaruh terhadap 
customer satisfaction. Di sisi lain, penelitian yang dilakukan oleh Livia dan Edwin (2015) menyatakan bahwa Self Image Congruity tidak berpengaruh terhadap Customer Satisfaction. Sementara itu masih sedikit penelitian tentang Self Image Congruity yang menggunakan produk berupa barang (pakaian atau lainnya) tetapi lebih fokus pada produk berupa jasa. Sementara menurut Schiffman dan Kanuk (2007) dalam Hartini (2012) fenomena self image congruity bukan hanya terjadi pada produk berupa jasa melainkan produk berupa barang. Jadi self image congruity adalah kecenderungan konsumen dalam membeli barang dan jasa yang mempunyai citra atau "kepribadian" yang sesuai dengan citra diri mereka.

Selain self image congruity, penelitian terdahulu yang dilakukan oleh Bhaskar dan Shekar (2011); Mehta, et al (2000), juga menekankan bahwa variable retail service quality juga turut memengaruhi customer satisfaction. Kualitas pelayanan bertujuan untuk memenuhi kebutuhan dan keinginan pelanggan serta ketepatan penyampaiannya dalam proses mengimbangi harapan pelanggan (Tjiptono, 2010). Penelitian terdahulu juga menyatakan bahwa customer perceived service quality berpengaruh terhadap customer satisfaction. Menurut Bitner dan Zeithaml (2003) perceived service qulity merupakan dasar dari terciptanya sebuah kualitas yang dapat digunakan untuk mengukur kepuasan pelanggan. Pelanggan merupakan subyek yang akan mengevaluasi sebuah kualitas layanan. Kualitas layanan ini didasarkan pada; kualitas interaksi (proses layanan disampaikan), kualitas lingkungan fisik (kualitas tempat terjadinya pelayanan), dan kualitas hasil (hasil pelayanan secara keseluruhan yang diterima oleh pelanggan).

Berdasarkan masalah tersebut maka penelitian ini akan mengaji variable self image congruity, retai service quality dan perceived service qualityyang diduga memengaruhi customer loyalty yang dimediasi variable customer satisfaction. Adapun tujuan penelitian ini adalah ingin mengaji apakah self image congruity, retail service quality, perceived service quality berpengaruh pada customer satisfaction? dan menguji peran mediasi variable customer satisfaction pada customer loyalty distro Urban Surf dan Planet Surf di Jayapura.

\section{METODE PENELITIAN}

Objek penelitian ini adalah distro Urban Surf dan Planet Surf. Pemilihan dua distro ini sebagai objek penelitian karena distro ini mampu menangkap fenomena self image congruity yaitu outlet/store yang menjual produk berupa pakaian, asesoris yang kental dengan citra diri anak muda yang enerjik dan penuh semangat serta produk yang tidak dijual secara massal. Adapun responden dalam penelitian ini adalah konsumen yang sudah lebih dari 3 kali menggunakan produk distro di berbagai tempat dan pernah lebih dari 2 kali berbelanja di Urban Surf maupun Planet Surf yang keputusannya dilakukan atas kehendak sendiri tanpa intervensi dari pihak manapun. Teknik pengumpulan data dilakukan dengan menggunakan kuesioner. Sebelum dibagikan kuesioner, untuk memastikan kuesioner diberikan kepada responden yang tepat, maka peneliti melakukan wawancara terlebih dahulu untuk menjamin bahwa responden pernah berbelanja di beberapa distro lainnya serta pernah berbelaja lebih dari 2 kali di distro Urban Surf maupun Planet Surf.

Penelitian ini menggunakan data primer yang diperoleh langsung dari responden yaitu pelanggan distro Urban Surf dan Planet Surf melalui hasil dari penyebaran kuesioner. Penelitian ini menggunakan data skunder yang meliputi data yang berasal dari literature-literatur, buku dan situssitus yang berhubungan dengan penelitian ini, termasuk penelitian-penelitian terdahulu. Penelitian ini menggunakan nonprobability sampling (Sekaran, 2006). Teknik yang digunakan purposive sampling (Cooper dan Schindler, 2006). Kriteria responden adalah responden yang sudah memiliki pekerjaan, dan memiliki kehendak atas dirinya sendiri dalam menentukan berbelanja yang dilakukan di distro 
Urban Surf dan Planet Surf sekurang-kurangnya 2 kali. Ukuran sampel dalam penelitian ini sebesar 100 responden. Penyebaran kuesioner dalam penelitian ini dilakukan kurang lebih selama 3 bulan, dari bulan September-November 2015.

Dalam penelitian ini peneliti mengadopsi intrumen pengukuran yang telah dikembangkan dan diuji validitas dan reliabilitas oleh peneliti-peneliti sebelumnya. Peneliti menggunakan skala Likert lima poin untuk setiap item pertanyaan variable independen maupun dependen. Adapun definisi operasional dan pengukuran intrumen penelitian yang digunakan untuk menguji hipotesis dan mengukur variable dijelaskan dalam Tabel 1.

Tabel 1. Definisi Operasional Variabel.

\begin{tabular}{|c|c|c|}
\hline Nama Variabel & Definisi Operasional & Indikator Variabel \\
\hline $\begin{array}{l}\text { Self Image } \\
\text { Congruity }\end{array}$ & $\begin{array}{l}\text { Kecenderungan konsumen Urban } \\
\text { Surf / Distro dalam membeli } \\
\text { barang/jasa yang mempunyai citra } \\
\text { atau "kepribadian" yang sesuai } \\
\text { dengan citra diri mereka. }\end{array}$ & $\begin{array}{l}\text { 1. Actual Self Image Congruity: } \\
\text { Kesesuaian antara citra diri actual } \\
\text { pembelanja dengan citra toko. } \\
\text { 2. Ideal Self Image Congruity: } \\
\text { Kesesuaian antara citra diri ideal } \\
\text { pembelanja dan citra toko Urban } \\
\text { Surf. } \\
\text { 3. Social Self Image Congruity: } \\
\text { Kesesuaian antara citra antara citra } \\
\text { diri sosial pembelanja dan citra } \\
\text { Urban Surf/Distro. } \\
\text { 4. Ideal Social Self Image Congruity: } \\
\text { Kesesuaian antar citra diri ideal- } \\
\text { sosial pembelanja dan citra Urban } \\
\text { Surf/DIstro. } \\
\text { (Interval Scale) }\end{array}$ \\
\hline $\begin{array}{l}\text { Retail Service } \\
\text { Quality }\end{array}$ & $\begin{array}{l}\text { Upaya pemenuhan kebutuhan dan } \\
\text { keinginan konsumen Distro serta } \\
\text { ketepatan penyampaiannya dalam } \\
\text { mengimbangi harapan pelanggan }\end{array}$ & $\begin{array}{l}\text { 1. Physical Aspect } \\
\text { Aspek fisik dari Urban } \\
\text { Surf/Distroyang meliputi berbagai } \\
\text { peralatan-peralatan atau fasilitas } \\
\text { yang bersifat tangibles dan } \\
\text { mempengaruhi kualitas layanan } \\
\text { yang diberikan kepada pelanggan. } \\
\text { 2. Reliability } \\
\text { Konsistensi Urban Surf/Distro dalam } \\
\text { memberikan layanan kepada } \\
\text { pelanggan berupa pemenuhan janji } \\
\text { yang diharapkan pelanggan. } \\
\text { 3. Personal Interaction } \\
\text { Kemampuan untuk menjalin } \\
\text { hubungan yang harmonis dengan } \\
\text { pelanggan dan hubungan ini } \\
\text { diarahkan untuk bisa memuaskan } \\
\text { pelanggan. }\end{array}$ \\
\hline
\end{tabular}


Tabel 1. Lanjutan

\begin{tabular}{|c|c|c|}
\hline Nama Variabel & Definisi Operasional & Indikator Variabel \\
\hline & & $\begin{array}{ll}\text { 4. } & \text { Problem Solving } \\
\text { Kemampuan yang dimiliki oleh } \\
\text { Urban Surf/Distro untuk } \\
\text { menyelesaikan berbagai masalah } \\
\text { yang dihadapi pelanggan. } \\
\text { 5. Policy } \\
\text { Berbagai kebijakan yang ditetapkan } \\
\text { untuk memberikan kemudahan, } \\
\text { kenyamanan bagi pelanggan. } \\
\text { (Interval Scale) }\end{array}$ \\
\hline $\begin{array}{l}\text { Customer } \\
\text { Perceived Service } \\
\text { Quality }\end{array}$ & $\begin{array}{l}\text { Penilaian pelanggan terhadap } \\
\text { kualitas layanan yang diberikan } \\
\text { oleh Urban Surf/Distro }\end{array}$ & $\begin{array}{l}\text { 1. Kualitas Interaksi } \\
\text { Kualitas yang berhubungan erat } \\
\text { dengan proses layanan Urban Surf } \\
\text { yang disampaikan kepada } \\
\text { pelanggan yang dimulai dari proses } \\
\text { interaksi staff penyedia layanan. } \\
\text { 2. } \text { Kualitas Lingkungan Fisik } \\
\text { Sebuah kualitas yang terjadi di } \\
\text { dalam lingkungan proses pelayanan } \\
\text { disampaikan kepada pelanggan. } \\
\text { 3. Kualitas Hasil } \\
\text { Hasil pelayanan yang diterima oleh } \\
\text { pelanggan berupa proses produksi } \\
\text { servis dan interaksi. } \\
\text { (Interval Scale) }\end{array}$ \\
\hline $\begin{array}{l}\text { Customer } \\
\text { Satisfaction }\end{array}$ & $\begin{array}{l}\text { Perasaan senang, sukacita, puas } \\
\text { yang dialami oleh pelanggan akan } \\
\text { kinerja produk baik barang/jasa } \\
\text { Urban Surf/Distro }\end{array}$ & $\begin{array}{l}\text { Customer Satisfaction } \\
\text { (Interval Scale) }\end{array}$ \\
\hline Customer Loyalty & $\begin{array}{l}\text { Kesetiaan pelanggan terhadap } \\
\text { produk baik barang maupun } \\
\text { layanan Urban Surf/Distro. }\end{array}$ & $\begin{array}{l}\text { Customer Loyalty } \\
\text { (Interval Scale) }\end{array}$ \\
\hline
\end{tabular}

Pengujian validitas dilakukan melalui Confirmatory Factor Analysis (CFA) dan sebelum dilakukan uji CFA maka perlu dilakukan uji Kaiser Meyer Olkin (KMO) dan Bartiett's Test untuk menguji ada tidaknya korelasi antar variable. Jika nilai $K M O$ berada pada batas 0,50 maka masih dapat ditoleransi untuk diterima sebagai instrument penelitian dengan signifikansi di bawah 0.05 . Sementara untuk uji reliabilitas digunakan koefisien Cronbach's Alpha dengan batas alpha sebesar 0,6 . Selanjutnya untuk analisis data dalam penelitian ini digunakan analisis multiple regression dan hierarical regression untuk mengukur variabel independen pada variabel dependen dengan variabel mediasi.

Secara matematis persamaan regresinya pengaruh langsung dan menguji variabel pemediasi adalah sebagai berikut:

$C S=a+\beta 1 S I C+\beta 2 R S Q+\beta 3 C P S Q+e$

$C L=a+\beta 4 C S+e$ 


$$
\begin{array}{ll}
C L & =a+\beta 1 S I C+\beta 2 R S Q+\beta 3 C P S Q+e \\
C L & =a+\beta 1 S I C+\beta 2 R S Q+\beta 3 C P S Q+\beta 4 C S+e
\end{array}
$$

Keterangan:

$$
\begin{array}{ll}
\mathrm{CS} & =\text { Customer Satisfaction } \\
\mathrm{SIC} & =\text { Self Image Congruity } \\
\mathrm{RSQ} & =\text { Retail Service Quality } \\
\mathrm{CPSQ} & =\text { Customer Perceived Service Quality } \\
\mathrm{CL} & =\text { Customer Loyalty } \\
\mathrm{a} & =\text { intercept } \\
\beta & =\text { konstanta } \\
\mathrm{e} & =\text { error term }
\end{array}
$$

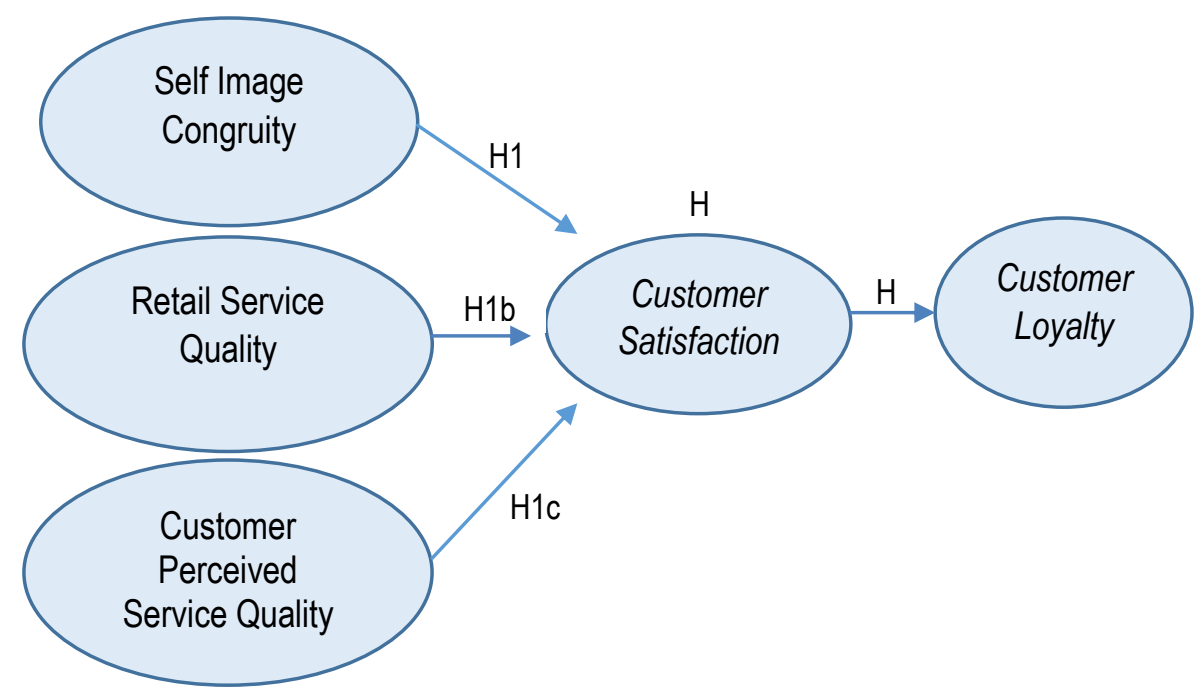

Gambar 1. Model penelitian

\section{HASIL DAN PEMBAHASAN}

Hasil penyebaran kuesioner kepada 100 responden dianalisis lebih lanjut dengan dilakukannya uji validitas dan reliabilitas. Uji validitas menggunakan CFA (Confirmatory Factor Analysis). Sebelum dilakukan uji CFA, dilakukan uji KMO (Kaiser Meyer Olkin). Hasil uji KMO ditunjukkan pada Tabel 2.

Tabel 2. KMO and Bartlett's Test

\begin{tabular}{|c|r|}
\hline Kaiser-Meyer-Olkin Measure of Sampling Adequacy. & 0,749 \\
Bartlett's Test of Sphericity Approx. Chi-Square & 968,684 \\
df & 210 \\
Sig. & 0,000 \\
\hline
\end{tabular}

Sumber: Data Primer Diolah 
Berdasarkan hasil perhitungan CFA awal, menunjukkan hasil validitas yang bisa diterima karena hampir semua item mempunyai factor loading yang lebih besar dari 0,50. Namun ada beberapa item pertanyaan yang nilainya di bawah 0,50 sehingga perlu dihilangkan dan kemudian dilakukan kembali uji CFA pada item yang tersisa yang memiliki nilai di atas 0,50 hingga semua item pertanyaan tidak ada lagi yang nilainya berada di bawah 0,50. Adapun hasil uji validitas akhir dari konfirmatori faktor analisis dapat dilihat pada Tabel 3.

Tabel 3. Rotated Component Matrixa

\begin{tabular}{|l|c|c|c|c|c|}
\hline & \multicolumn{5}{|c|}{ Component } \\
\cline { 2 - 6 } & 1 & 2 & 3 & 4 & 5 \\
\hline SIC1 & 0,828 & & & & \\
SIC2 & 0,710 & & & & \\
SIC3 & 0,828 & & & & \\
SIC4 & 0,794 & & & & \\
SIC5 & 0,740 & & & & \\
SIC6 & 0,705 & & & & \\
SIC7 & 0,734 & & & & \\
RSQ1 & & & 0,499 & & \\
RSQ3 & & & 0,754 & & \\
RSQ4 & & & 0,797 & & \\
RSQ5 & & & 0,799 & & \\
CPSQ1 & & & & 0,662 & \\
CPSQ2 & & & & 0,706 & \\
CPSQ3 & & & & 0,824 & \\
CPSQ5 & & & & 0,558 & \\
CS3 & & 0,747 & & & \\
CS4 & & 0,812 & & & \\
CS5 & & 0,862 & & & 0,842 \\
CL4 & & & & & 0,731 \\
CL5 & & & & \\
\hline
\end{tabular}

Sumber: Data Primer Diolah

Adapun hasil pengujian reliabilitas instrument pengukuran variabel-variabel independen dijelaskan pada Tabel 4. 
Tabel 4. Uji Reliabilitas Variabel Independen

\begin{tabular}{lc}
\hline \multicolumn{1}{c}{ Variabel } & Cronbach's Apha \\
\hline Self Image Congruity & 0,879 \\
Retail Service Quality & 0,751 \\
Customer Perceived Service & 0,677 \\
Quality & \\
Customer Satisfaction & 0,841 \\
Customer Loyalty & 0,574 \\
\hline
\end{tabular}

Dalam penelitian ini untuk uji hipotesis pengaruh langsung maupun uji hipotesis dengan variabel mediasi, peneliti menggunakan analisis multiple regression dan hierarical regression untuk menguji keseluruhan hipotesis yang diajukan. Analisis ini digunakan untuk menguji hubungan dan pengaruh antara variabel bebas dan variabel terikat yang memiliki skala pengukuran interval. Pada Tabel 5 dijelaskan hasil uji hipotesis pengaruh Self Image Congruity, Retail Service Quality, Customer Perceived Service Quality pada Customer Satisfaction. Hasil menunjukkan bahwa Self Image Congruity, Retail Service Quality, Customer Perceived Service Quality berpengaruh positif signifikan terhadap Customer Satisfaction dengan signifikansi 0,002 (SIC), 0,044 (RSQ), 0,015 (CPSQ) dengan nilai beta sebesar 0,244 (SIC), 0,240 (RSQ), 0,241 (CPSQ). dengan demikian hipotesis 1a, 1b, dan 1c diterima.

Tabel 5. Hasil Uji Hipotesis 1

\begin{tabular}{|c|c|c|c|c|c|c|}
\hline & \multirow{2}{*}{ Model } & \multicolumn{2}{|c|}{ Unstandardized Coefficients } & \multirow{2}{*}{$\begin{array}{c}\text { Standardized } \\
\text { Coefficients } \\
\text { Beta }\end{array}$} & \multirow{2}{*}{$t$} & \multirow{2}{*}{ Sig. } \\
\hline & & B & Std. Error & & & \\
\hline \multirow[t]{4}{*}{1} & (Constant) & 1,294 & 0,574 & & 2,255 & 0,026 \\
\hline & SIC & 0,244 & 0,078 & 0,286 & 3,137 & 0,002 \\
\hline & $\mathrm{RSQ}$ & 0,240 & 0,117 & 0,193 & 2,045 & 0,044 \\
\hline & CPSQ & 0,241 & 0,097 & 0,232 & 2,475 & 0,015 \\
\hline
\end{tabular}

Sumber: Data Primer Diolah

Selanjutnya dilakukan pengujian hipotesis kedua yaitu menguji variable Customer Satisfaction terhadap Customer Loyalty. Adapun hasil pengujian hipotesis 2 menunjukkan bahwa Customer Satisfaction berpengaruh terhadap Customer Loyalty ditujukan dengan nilai signifikansi 0,039 dan beta sebesar 0,136. hasil perhitungan ditujukan pada Tabel 6 .

Tabel 6. Hasil Uji Hipotesis 2

\begin{tabular}{|cc|c|c|c|c|c|}
\hline \multirow{2}{*}{ Model } & \multicolumn{2}{|c|}{ Unstandardized Coefficients } & $\begin{array}{c}\text { Standardized } \\
\text { Coefficients }\end{array}$ & \multirow{2}{*}{$t$} & \multirow{2}{*}{ Sig. } \\
\cline { 2 - 5 } & B & Std. Error & Beta & & \\
\hline 1 & (Constant) & 3,579 & 0,342 & & 10,461 & 0,000 \\
& CS & 0,163 & 0,078 & 0,207 & 2,092 & 0,039 \\
\hline
\end{tabular}


Sementara itu untuk uji hipotesis 3 yaitu menguji peran mediasi, apakah Customer Satisfaction memediasi pengaruh Self Image Customer, Retail Service Quality, Customer Perceived Service Quality terhadap Customer Loyalty. Untuk menguji peran variable mediasi, maka sesuai Baron dan Kenny (1986) maka akan dilakukan pengujian tahap pertama yaitu menguji SIC, RSQ, CPSQ terhadap CL. Hasil perhitungan dapat dilihat pada Tabel 7, 8, dan 9.

Tabel 7. Hasil Pengujian Variabel SIC Terhadap CL

\begin{tabular}{|cc|c|c|c|c|c|}
\hline \multirow{2}{*}{ Model } & \multicolumn{2}{|c|}{ Unstandardized Coefficients } & $\begin{array}{c}\text { Standardized } \\
\text { Coefficients }\end{array}$ & \multirow{2}{*}{$t$} & \multirow{2}{*}{ Sig. } \\
\cline { 2 - 5 } & B & Std. Error & Beta & & \\
\hline 1 & (Constant) & 3,555 & 0,279 & & 12,763 & 0,000 \\
& SIC & 0,175 & 0,066 & 0,260 & 2,661 & 0,009 \\
\hline
\end{tabular}

Sumber: Data Primer Diolah

Tabel 8. Hasil Pengujian Variabel RSQ Terhadap CL

\begin{tabular}{|cc|c|c|c|c|c|}
\hline \multirow{2}{*}{ Model } & \multicolumn{2}{|c|}{ Unstandardized Coefficients } & $\begin{array}{c}\text { Standardized } \\
\text { Coefficients }\end{array}$ & \multirow{2}{*}{$t$} & \multirow{2}{*}{ Sig. } \\
\cline { 3 - 5 } & B & Std. Error & Beta & & \\
\hline 1 & (Constant) & 3,221 & 0,408 & & 7,891 & 0,000 \\
& RSQ & 0,252 & 0,096 & 0,257 & 2,630 & 0,010 \\
\hline
\end{tabular}

Sumber: Data Primer Diolah

Tabel 9. Hasil Pengujian Variabel CPSQ Terhadap CL

\begin{tabular}{|cc|c|c|c|c|c|}
\hline \multirow{2}{*}{ Model } & \multicolumn{2}{|c|}{ Unstandardized Coefficients } & $\begin{array}{c}\text { Standardized } \\
\text { Coefficients }\end{array}$ & \multirow{2}{*}{$t$} & \multirow{2}{*}{ Sig. } \\
\cline { 3 - 5 } & B & Std. Error & Beta & & \\
\hline 1 & (Constant) & 3,739 & 0,348 & & 10,747 & 0,000 \\
& CPSQ & 0,131 & 0,082 & 0,159 & 1,592 & 0,115 \\
\hline
\end{tabular}

Sumber: Data Primer Diolah

Setelah tahap pertama dilakukan maka dilanjutkan pada tahap kedua yaitu menguji variabel SIC, RSQ, CPSQ terhadap CS. Hasil perhitungan ini sudah ditampilkan sebelumnya pada Tabel 5. Namun untuk hasil perhitungan secara detil dapat dilihat pada tabel 10, 11, dan 12.

Tabel 10. Hasil Pengujian Variabel SIC Terhadap CS

\begin{tabular}{|cc|c|c|c|c|c|}
\hline \multirow{2}{*}{ Model } & \multicolumn{2}{|c|}{ Unstandardized Coefficients } & $\begin{array}{c}\text { Standardized } \\
\text { Coefficients }\end{array}$ & \multirow{2}{*}{$t$} & \multirow{2}{*}{ Sig. } \\
\cline { 3 - 5 } & $\mathrm{B}$ & Std. Error & Beta & & \\
\hline 1 & (Constant) & 3,061 & 0,341 & & 8,987 & 0,000 \\
& SIC & 0,308 & 0,080 & 0,362 & 3,838 & 0,000 \\
\hline
\end{tabular}

Sumber: Data Primer Diolah 
Tabel 11. Hasil Pengujian Variabel CPSQ Terhadap CS

\begin{tabular}{|cc|c|c|c|c|c|}
\hline \multirow{2}{*}{ Model } & \multicolumn{2}{|c|}{ Unstandardized Coefficients } & $\begin{array}{c}\text { Standardized } \\
\text { Coefficients }\end{array}$ & \multirow{2}{*}{$t$} & \multirow{2}{*}{ Sig. } \\
\cline { 3 - 5 } & B & Std. Error & Beta & & \\
\hline 1 & (Constant) & 2,654 & 0,506 & & 5,243 & 0,000 \\
& RSQ & 0,401 & 0,119 & 0,323 & 3,379 & 0,001 \\
\hline
\end{tabular}

Sumber: Data Primer Diolah

Tabel 12. Hasil Pengujian Variabel CPSQ Terhadap CL

\begin{tabular}{|cc|c|c|c|c|c|}
\hline \multirow{2}{*}{ Model } & \multicolumn{2}{|c|}{ Unstandardized Coefficients } & $\begin{array}{c}\text { Standardized } \\
\text { Coefficients }\end{array}$ & \multirow{2}{*}{$t$} & \multirow{2}{*}{ Sig. } \\
\cline { 3 - 5 } & B & Std. Error & Beta & & \\
\hline 1 & (Constant) & 2,890 & 0,421 & & 6,870 & 0,000 \\
& CPSQ & 0,348 & 0,099 & 0,334 & 3,508 & 0,001 \\
\hline
\end{tabular}

Sumber: Data Primer Diolah

Tahap ketiga menguji pengaruh SIC, RSQ dan CPSQ bersama-sama dengan CS terhadap CL. Hasil perhitungan ditampilkan pada Tabel 13.

Tabel 13. Hasil Pengujian SIC, RSQ dan CPSQ Terhadap CS

\begin{tabular}{|c|c|c|c|c|c|c|}
\hline & \multirow{2}{*}{ Model } & \multicolumn{2}{|c|}{ Unstandardized Coefficients } & \multirow{2}{*}{$\begin{array}{c}\begin{array}{c}\text { Standardized } \\
\text { Coefficients }\end{array} \\
\text { Beta }\end{array}$} & \multirow{2}{*}{$t$} & \multirow{2}{*}{ Sig. } \\
\hline & & B & Std. Error & & & \\
\hline \multirow[t]{5}{*}{1} & $\overline{\text { (Constant) }}$ & 2,597 & 0,505 & & 5,143 & 0,000 \\
\hline & CS & 0,048 & 0,087 & 0,061 & 0,550 & 0,584 \\
\hline & CPSQ & 0,045 & 0,086 & 0,054 & 0,518 & 0,606 \\
\hline & RSQ & 0,177 & 0,103 & 0,181 & 1,725 & 0,088 \\
\hline & SIC & 0,129 & 0,070 & 0,192 & 1,845 & 0,068 \\
\hline
\end{tabular}

Sumber: Data Primer Diolah

Dari hasil perhitungan pengujian hipotesis 3,diketahui bahwa CS memediasi penuh hubungan pengaruh SIC, RSQ, terhadap CL karena memenuhi kondisi sebagai berikut:

1. Variabel SIC, RSQ, dan CPSQ berpengaruh signifikan secara langsung pada CS.

2. Variabel SIC, RSQ, dan CPSQ berpengaruh signifikan secara langsung pada $C L$.

3. Variabel CS berpengaruh signifikan secara langsung pada CL.

4. Pengaruh mediasi penuh (full mediation) terjadi jika pengaruh SIC, RSQ, dan CPSQ pada CL yang semula signifikan menjadi tidak berpengaruh signifikan ketika variabel CS diregresikan secara bersama-sama. Sedangkan mediasi sebagian (partial mediation) akan terjadi apabila signifikansi variabel SIC, RSQ, dan CPSQ menurun tapi tetap signifikan terhadap variabel CL pada saat variabel CS diregresikan secara bersama-sama. Mediasi sebagian (partial mediation) 
juga terjadi apabilah variabel SIC, RSQ, dan CPSQ hanya berpengaruh langsung terhadap CS ketika dilakukan uji mediasi.

Namun dalam hasil perhitungan pengujian hipotesis juga diketahui bahwa CS memediasi secara parsial pada hubungan pengaruh CPSQ terhadap CL karena hanya memenuhi 1 dari 3 syarat yang telah ditentukan (Baron dan Kenny, 1986).

Berikut ditampilkan hasil uji mediasi secara lebih mendetil, pada Tabel 14.

Tabel 14.

\begin{tabular}{|c|c|c|c|c|}
\hline STEP 1 & Beta & t-value & Sig. & Keterangan \\
\hline $\mathrm{SIC} \rightarrow \mathrm{CL}$ & 0,175 & 2,261 & 0,009 & Signifikan \\
\hline $\mathrm{RSQ} \longrightarrow \mathrm{CL}$ & 0,252 & 2,630 & 0,010 & Signifikan \\
\hline $\mathrm{CPSQ} \longrightarrow \mathrm{CL}$ & 0,131 & 1,592 & 0,115 & Tidak Signifikan \\
\hline \multicolumn{5}{|l|}{ STEP 2} \\
\hline $\mathrm{SIC} \rightarrow \mathrm{CS}$ & 0,308 & 3,838 & 0,000 & Signifikan \\
\hline $\mathrm{RSQ} \longrightarrow \mathrm{CS}$ & 0,401 & 3,379 & 0,001 & Signifikan \\
\hline $\mathrm{CPSQ} \longrightarrow \mathrm{CS}$ & 0,348 & 3,508 & 0,001 & Signifikan \\
\hline \multicolumn{5}{|l|}{ STEP 3} \\
\hline $\mathrm{SIC} \rightarrow \mathrm{CL}$ & 0,129 & 1,845 & 0,068 & Tidak Signifikan \\
\hline $\mathrm{RSQ} \longrightarrow \mathrm{CL}$ & 0,177 & 1,725 & 0,088 & Tidak Signifikan \\
\hline $\mathrm{CPSQ} \longrightarrow \mathrm{CL}$ & 0,045 & 0,518 & 0,606 & Tidak Signifikan \\
\hline $\mathrm{CS} \rightarrow \mathrm{CL}$ & 0,048 & 0,550 & 0,584 & Tidak Signifikan \\
\hline
\end{tabular}

Sumber: Data Primer Diolah

Dari rincian Tabel 14 diketahui bahwa pengaruh variabel SIC dan RSQ yang semula memiliki pengaruh signifikan secara langsung pada CS dan CL, menjadi tidak signifikan ketika kedua variabel bebas tersebut diregresikan bersama-sama dengan CS terhadap CL. Sementara itu untuk variabel CPSQ hanya memiliki pengaruh langsung secara signifikan terhadap CS. Sehingga variabel pemediasi CS hanya memediasi secara parsial hubungan CPSQ terhadap CL.

Self Image Congruity berpengaruh positif terhadap Customer Satisfaction. Hasil penelitian ini sejalan dengan penelitian yang dilakukan oleh Jamal dan Goode (2001); Wilkins, et al (2006), Park dan Lee, (2005). Namun hasil penelitian ini berbeda dengan penelitian yang dilakukan oleh Livia dan Edwin (2015) yang meneliti tentang self image congruity pada kepuasan pelanggan Broadway Barbershop, hasil yang berbeda ini mungkin saja disebabkan karena perbedaan konteks penelitian antara konteks jasa dengan retail barang. Hasil penelitian ini juga menunjukkan bahwa semakin tinggi self image congruity yang dirasakan pelanggan Urban Surf/Distro di Jayapura maka semakin tinggi kepuasan yang dirasakan oleh pelanggan Urban Surf/Distro di Jayapura.

Retail Service Quality berpengaruh positif terhadap Customer Satisfaction. Hasil penelitian ini memperkuat penelitian yang dilakukan oleh Livia dan Edwin (2015); Ushantha et al.,(2014); dan juga Beneke et al.,(2012). Hal ini menunjukkan bahwa semakin baik retail service quality suatu distro maka semakin tinggi kepuasan yang dirasakan oleh pelanggan distro, khususnya pelanggan DistrolUrban Surf/Planet Surf.

Customer Perceived Service Quality berpengaruh positif terhadap Customer Satisfaction. Hasil penelitian ini konsisten dengan hasil penelitian yang dilakukan oleh Livia dan Edwin (2015); Mehdi et al.,(2013). Jadi semakin baik persepsi pelanggan akan kualitas pelayanan yang diterima 
saat berbelanja di distro/Urban Surf maka semakin tinggi kepuasan yang dialami oleh pelanggan distro/Urban Surf.

Customer Satisfaction berpengaruh positif terhadap Customer Loyalty. Hasil temuan ini semakin memperkuat teori sebelumnya bahwa kepuasan pelanggan akan berdampak pada kesetiaan pelanggan. Temuan penelitian ini senada dengan penelitian yang dilakukan oleh Mohsan et al., (2011); Anantha (2013). Semakin tinggi kepuasan yang dialami oleh pelanggan distro/Urban Surf maka semakin tinggi tingkat loyalitas pelanggan Urban Surf/Distro.

Customer Satisfaction memediasi hubungan Self Image Congruity, Retail Service Quality, Customer Perceived Service Quality terhadap Customer Loyalty. Hasil penelitian ini membuktikan bahwa sebelum pelanggan merasa puas, maka pelanggan harus merasakan bahwa citra barang yang digunakan sesuai dengan citra diri atau "kepribadian" pelanggan. Selanjutnya persepsi pelanggan akan kualitas layanan yang disampikan oleh Urban Surf juga turut memengaruhi kepuasan pelanggan. Kualitas layanan yang dirasakan pelanggan selama berbelanja juga turut memengaruhi kepuasan pelanggan sehingga pada akhirnya ketika pelanggan merasakan kepuasan akan membuat pelanggan menjadi loyal akan produk yang ditawarkan oleh Urban Surf/Distro di Jayapura. Penelitian ini semakin memperlengkapi penelitian sebelumnya dengan menggunakan variabel yang belum digunakan dan penelitian ini juga menggunakan produk berupa barang, yang mana pada penelitian sebelumnya cenderung menggunakan produk berupa jasa. Sehingga penelitian ini menguatkan teori sebelumnya yang dinyatakan oleh Schiffman dan Kanuk (2007) dalam Hartini (2012).

\section{PENUTUP}

Dari hasil penelitian yang telah dikemukan di atas, maka manajer pemasaran distro dalam hal ini manajer Urban Surf untuk terus berinovasi mengembangkan citra produk mengikuti perkembangan tren anak muda di Jayapura sehingga sesuai dengan citra diri atau "kepribadian" pelanggan Urban Surf. Urban Surf sebagai salah satu distro di Jayapura juga perlu meningkatkan layanan yang akan disampaikan kepada pelanggan selama proses berbelanja sehingga akan membuat pelanggan Urban Surf semakin puas dan akan meningkatkan loyalitas pelanggan Urban Surf.

\section{REFERENSI}

Anantha Raj A. Arokiasamy. (2013). The Impact of Customer Satisfaction on Customer Loyalty and Intention to Switch in The Banking Sector in Malaysia. Journal of Commerce, Jan 2013, Vol. 5. Issue 1, p14.

Beneke J.,et al. (2012). Examining the Effect of Retail Service Quality Dimensions on Customer Satisfaction and Loyalty: The Case of he Supermaket Shopper. Independent Research Journal in The Management Sciences. Vol 12, No 1 (2012). Acta Commercii. AOSIS Publishing.

Bitner, M. \& Zeithaml, V. (2003). Service Marketing (3rd ed.). New Delhi: Tata McGraw Hill. Cooper, D. R. \& Schindler, P.S. (2006). Business Research Methods 9th ed, New York; McGraw Hill. Hartini Sri. (2012). Self-Image Congruity: Role in The Formation of Consumer Attitudes. Entrepreneur Journal. Vol. 3, No. 1. Unipdu.

https://id.wikipedia.org/wiki/Distro_pakaian 
Jamal, Ahmad \& Mark M. H. Goode. (2001). Consumers and Brands: A Study of Self Image Congruence on Brand Preference and Satisfaction. Marketing Intelligence \& Planning. Vol.19/7. pp: 482-492.

Livia Margarita Widjiono \& Edwin Japarianto. (2015). Analisa Pengaruh Self Image Congruity, Retail Service Quality, Dan Customer Perceived Service Quality Terhadap Repurchase Intention Dengan Customer Satisfaction Sebagai Variabel Intervening Di Broadway Barbershop Surabaya. Jurnal Manajemen Pemasaran, Vol. 9, No 1, April 2015, ISSN 1907-235X.

Mehdi Zaibal et al. (2013). Effect Perceived Service Quality on Customer Satisfaction in Hospitality Industry: Gronroos' Service Quality Model Development. Journal of Hospitality Marketing \& Management, Vol. 22, Issue 5, 2013.

Mohsan Faizan et al.,(2011). Impact of Customer Satisfaction on Customer Loyalty and Intention to Switch: Evidence From Banking Sector of Pakistan. International Journal of Business \& Social Science, 2011, Vol. 2 Issue 16, p263.

papua.bps.go.id

Park S.Y. \& Lee E.M. (2005). Congruencevbetween brand personality and self-image, and the mediating roles of satisfaction and consumer-brand relationship on brand loyalty. Asia-Pacific Advances in Consumer Research, Vol. 6, 39-45.

Schiffman Leon \& Kanuk Leslie. (2007). Consumer Behaviored ${ }^{10}$, Prentice Hall Cloth.

Sekaran, U. (2006). Metodologi Penelitian untuk Bisnis, edisi 4. Jakarta: Salemba Empat.

Tjiptono, Fandy. (2010). Strategi Pemasaran, Yogyakarta: Penerbit Andi.

Ushantha Chanaka et al. (2014). An Assessment of Retail Service Quality: An Empirical Study of the RSQS in Sri Lanka Supermarkets. Developing Country Studies, 4(3), 78-90, 2014. Social Sience Electronic Publishing, Inc. 